\title{
Polymyalgia rheumatica with normal inflammatory indices at the time of diagnosis: can we just move a step forward?
}

\author{
Ciro Manzo' ${ }^{1}$, Marcin Milchert ${ }^{2}$, Maria Natale ${ }^{1}$, Marek Brzosko² \\ ${ }^{1}$ Internal and Geriatric Medicine Department, Rheumatologic Outpatient Clinic Hospital “Mariano Lauro”, Sant’Angello, Italy \\ ${ }^{2}$ Department of Rheumatology, Internal Medicine, Geriatrics and Clinical Immunology, Pomeranian Medical University in Szczecin, \\ Poland
}

\begin{abstract}
The existence of polymyalgia rheumatica (PMR) with normal inflammatory indices at the time of diagnosis still represents a diagnostic conundrum. According to the literature, some patients with PMR following immune checkpoint inhibitory therapy had normal values of both erythrocyte sedimentation rate and $\mathrm{C}$-reactive protein concentrations at the time of diagnosis.

In this short communication we investigated the possibility that in some patients with PMR the main pathogenic mechanism is constituted by inhibition of some checkpoints, such as programmed death receptor-1, programmed death ligand 1, and "cytotoxic" lymphocyte antigen 4. In these patients, the pathogenetic mechanisms underlying PMR can act much more upstream than commonly suggested. Also, we addressed the question of whether these patients should be considered as affected by PMR-like syndromes or by PMR subset.
\end{abstract}

Key words: polymyalgia rheumatica, checkpoint inhibitory therapy, checkpoint inhibitors, inflammatory indices.

Initial raised values of erythrocyte sedimentation rate (ESR) and C-reactive protein (CRP) concentrations are typical findings in patients with polymyalgia rheumatica (PMR), and they are present in all its diagnostic and classification proposed criteria [1]. An international collaborative initiative between the European League Against Rheumatism (EULAR) and the American College of Rheumatology (ACR) proposed new classification criteria in 2012. According to them, the age of 50 years or older, bilateral shoulder aching and abnormal CRP and/or ESR were considered required criteria [2].

In an editorial published in Reumatologia in 2018, we highlighted the possibility that, in an older person complaining of chronic bilateral shoulder and hip girdle pain associated with inflammatory morning stiffness, PMR can be considered even if ESR and CRP are both normal, and we proposed a four-point guidance [3]. In a case series published in 2019, among 460 PMR patients we identified seven (1.52\%) with normal values of both ESR and CRP concentrations at the time of diagnosis. In these seven patients, all PMR-mimicking diseases were excluded during follow-ups lasting from 29 to 120 months [4].

Since 2011, when ipilimumab was first approved for metastatic melanoma, immune checkpoint inhibitors (ICls) have been receiving an increasing number of indications in cancer patients [5-7]. As is known, ICls act by blocking some co-stimulatory molecules such as cytotoxic lymphocyte antigen 4 (CTLA-4), programmed death protein 1 (PD-1), programmed death ligand 1 (PD-L1), localized on T cells, antigen presenting cells and cancer cells. As a consequence of such inhibition, T cell activation and development of regulatory $T$ cells (Tregs) are suppressed [8].

Among immune rheumatic adverse events associated with ICIS, PMR is frequently reported both as case reports and case series [9-14]. In a recent study on pharmacovigilance, a fivefold elevated risk for developing

Address for correspondence:

Ciro Manzo, Internal and Geriatric Medicine Department ASL NA sud, Rheumatologic Outpatient Clinic Hospital “Mariano Lauro”, viale dei Pini 1, 80065 Sant'Angello, Italy, e-mail: manzoreumatologo@libero.it

Submitted: 13.02.2020; Accepted: 20.04.2020 
PMR was highlighted in cancer patients treated with ICls versus those not treated [15]. In some of these patients, clinical and/or laboratory findings have been considered atypical, so that PMR-like syndrome was diagnosed. For example, in 2019 Calabrese et al. [9] published the characteristics of 20 patients from three centres: 6/20 (30\%) had normal inflammatory markers at the time of PMR diagnosis. However, it must be highlighted that in three of these (patients no. $4,9,14$ ) there were other findings (i.e. positivity for rheumatoid factor, knee involvement, treatment with prednisone $60 \mathrm{mg} /$ day) that could not be compatible with this diagnosis [16].

Pathogenesis of PMR is debated [17-20]. According to our best knowledge, the activation of the immune checkpoints in PMR has not yet been studied. Nevertheless, the onset of PMR manifestations following ICls might suggest their potential role in its pathogenesis.

On the other hand, an impaired PD-1 immune checkpoint has been proved again and again in giant cell arteritis (GCA). Indeed, in GCA-affected arteries a deficiency of the PD-1 immune checkpoint on dendritic cells (DCs) fails to inhibit interacting PD-1+T cells. As a consequence, uninhibited T cells overexpress [21, 22]. GCA is a vasculitis frequently associated with PMR, in most studies estimated between 10\% and 30\% [23]. However, the pathogenetic link between PMR and GCA is still not fully elucidated [24, 25], and all that is known for GCA cannot be applied to isolated PMR.

Recently there was an intriguing proposal to redefine PMR from inflammatory musculoskeletal syndrome to "inflammatory disease of musculotendinous structures" originating from peritendineum and perimysium [26]. The questions arises whether such localised autoimmunisation, possibly triggered by checkpoints inhibitors, could happen instead of being triggered by innate immunity activation with its traditional inflammatory markers. We are looking forward to comparative MRI studies in checkpoint inhibitor induced PMR.

Hence, future appropriately designed studies are needed. In the meantime, we can speculate that in some PMR patients the pathogenetic mechanisms act much more upstream than commonly considered. If this working hypothesis were proved correct, a new subset of disease having normal inflammatory indices (and not PMR-like syndrome) would be possible.

However, detailed definition of such a subset of disease must be provided to avoid overdiagnosis, as "secondary PMR" currently does not exist. A validation of musculoskeletal imaging utility in inflammatory marker negative PMR cases could be advocated as well as possibly higher cut-off values for PMR in classification criteria scores.

\section{Conclusions}

The onset of PMR cases in patients treated with ICl therapy suggests a potential role of immune checkpoint signals (PD-1 and PD-L1, above all) in PMR pathogenesis.

The fact that some of these cases had normal inflammatory indices at the time of diagnosis, as PMR patients (not treated with $\mathrm{ICl}$ therapy), in our case series suggests that a subset of disease, in which the impairment of these signals is relevant, can exist.

The authors declare no conflict of interest.

\section{References}

1. Bird HA, Leeb BF, Montecucco CM, et al. A comparison of the sensitivity of diagnostic criteria for polymyalgia rheumatica. Ann Rheum Dis 2005; 64: 626-629, DOI: 10.1136/ ard.2004.025296.

2. Dasgupta B, Cimmino MA, Kremers HM, et al. 2012 Provisional Classification Criteria for Polymyalgia Rheumatica: A European League Against Rheumatism/American College of Rheumatology Collaborative Initiative. Ann Rheum Dis 2012; 71: 484492, DOI: 10.1136/annrheumdis-2011-200329.

3. Manzo C, Milchert M. Polymyalgia rheumatica with normal values of both erythrocyte sedimentation rate and C-reactive protein concentration at the time of diagnosis: a fourpoint guidance. Reumatologia 2018; 56: 1-2, DOI: 10.5114/ reum.2018.74740.

4. Manzo C, Milchert M, Natale M, Brzosko M. Polymyalgia Rheumatica With Normal Values of Both Erythrocyte Sedimentation Rate and C-reactive Protein Concentration at the Time of Diagnosis. Rheumatology (Oxford) 2019; 5: 921-923, DOI: 10.1093/rheumatology/key431.

5. Topalian SL, Drake CG, Pardoll DM. Immune Checkpoint Blockade: A Common Denominator Approach in Cancer Therapy. Cancer Cell 2015; 27: 450-461, DOI: 10.1016/j. ccell.2015.03.001.

6. Hargadon KM, Johnson CE, Williams CJ. Immune Checkpoint Blockade Therapy for Cancer: An Overview of FDA approved Immune Checkpoint Inhibitors. Int Immunopharmacol 2018; 62: 29-39, DOI: 10.1016/j.intimp.2018.06.001.

7. Wolchok JD, Neyns B, Linette G, et al. Ipilimumab Monotheraphy in Patients With Pretreated Advanced Melanoma: A Randomized, Double-Bind, Multicentre, Phase 2, Dose-Ranging Study. Lancet Oncol 2010; 1: 155-164, DOI: 10.1016/S14702045(09)70334-1.

8. He XS, Gershwin ME, Ansari AA. Checkpoint-based Immunotherapy for Autoimmune Diseases - Opportunities and Challenges. J Autoimmun 2017; 79: 1-3, DOI: 10.1016/j. jaut.2017.02.004.

9. Calabrese LH, Calabrese C, Cappelli LC. Rheumatic Immune-Related Adverse Events From Cancer Immunotherapy. Nat Rev Rheumatol 2018; 14: 569-579, DOI: 10.1038/s41584-0180074-9.

10. Richter MD, Crowson C, Kottschade LA, et al. Rheumatic Syndromes Associated With Immune Checkpoint Inhibitors: A Sin- 
gle-Center Cohort of Sisty-One Patients. Arthritis Rheumatol 2019; 71: 468-475, DOI: 10.1002/art.40745.

11. Shahin J, Hudson M, Fifi-Mah A, Ye C. Immune-related Adverse Events Associated With Cancer Immunotherapy: A Review for the Practicing Rheumatologist. J Rheumatol 2020; 47: 156175, DOI: 10.3899/jrheum.190084.

12. Chan KK, Bass AR. Checkpoint Inhibitor-Induced Polymyalgia Rheumatica Controlled by Cobimetinib, a MEK $1 / 2$ Inhibitor Ann Rheum Dis 2019; 78: e70, DOI: 10.1136/annrheumdis-2018-213672.

13. Garel B, Krankimel N, Trouvin AP, et al. Pembrolizumab-induced Polymyalgia Rheumatica in Two Patients With Metastatic Melanoma. Joint Bone Spine 2017; 84: 233-234, DOI 10.1016/j.jbspin.2016.01.007.

14. Kuswanto WF, MacFarlane LA, Gedmintas L, et al. Rheumatologic Symptoms in Oncologic Patients on PD-1 Inhibitors. Semin Arthritis Rheum 2018; 47: 907-910, DOI: 10.1016/j. semarthrit.2017.10.018.

15. Salem JE, Manouchehri A, Moey M, et al. Cardiovscular Toxicities Associated With Immune Checkpoint Inhibitors: An Observational, Retrospective, Pharmacovigilance Study. Lancet Oncol 2018; 19: 1579-1589, DOI: 10.1016/S1470-2045(18)30608-9.

16. Calabrese C, Cappelli LC, Kostine M, et al. Polymyalgia rheumatica-like syndrome from chreckpoint inhibitor therapy: case series and systematic review of the literature. RMD Open 2019; 5: e000906, DOI: 10.1136/rmdopen-2019-000906.

17. Guggino G, Ferrante A, Macaluso F, et al. Pathogenesis of Polymyalgia Rheumatica. Reumatismo 2018; 70: 10-17, DOI 10.4081/reumatismo.2018.1048

18. Boiardi L, Casali B, Farnetti E, et al. Relationship Between Interleukin 6 Promoter Polymorphism at Position -174, IL-6 Serum Levels, and the Risk of Relapse/Recurrence in Polymyalgia Rheumatica. J Rheumatol 2006; 33: 703-708.
19. Doria A, Zen M, Bettio S, et al. Autoinflammation and Autoimmunity: Brindging the Divide. Autoimmun Rev 2012; 12: 2230, DOI: 10.1016/j.autrev.2012.07.018.

20. Bonafè $M$, Olivieri $F$, Cavallone L, et al. A Gender-Dependent Genetic Predisposition to Produce High Levels of IL- 6 is Detrimental for Longevity. Eur J Immunol 2001; 31: 2357-2361, DOI: 10.1002/1521-4141(200108)31:8\&\#60.

21. Zhang H, Watanabe R, Berry GJ, et al. Immunoinhibitory Checkpoint Deficiency in Medium and Large Vessel Vasculitis. Proc Natl Acad Sci USA 2017; 114: E970-E979, DOI: 10.1073/ pnas.1616848114.

22. Weyand CM, Berry GJ, Goronzy JJ. The Immunoinhibitory PD-1/ PD-L1 Pathway in Inflammatory Blood Vessel Disease. J Leukoc Biol 2018; 103: 565-575, DOI: 10.1189/jlb.3MA0717-283.

23. Gonzalez-Gay MA. Giant Cell Arteritis and Polymyalgia Rheumatica: Two Different but Often Overlapping Conditions. Semin Arthritis Rheum 2004; 33: 289-293, DOI: 10.1016/j. semarthrit.2003.09.007.

24. Buttgereit F, Dejaco C, Matteson EL, Dasgupta B. Polymyalgia Rheumatica and Giant Cell Arteritis: Systematic Review. JAMA 2016; 315: 2442-2458, DOI: 10.1001/jama.2016.5444.

25. Milchert M, Brzosko M. Diagnosis of Polymyalgia Rheumatica Usually Means a Favourable Outcome for Your Patient. Indian J Med Res 2017; 145: 593-600, DOI: 10.4103/ijmr.IJMR_298_17. 26. Owen CE, Liew DFL, Buchanan RRC. Musculotendinous Inflammation: The Defining Pathology of Polymyalgia Rheumatica? J Rheumatol 2019; 46: 1552-1555, DOI: 10.3899/ jrheum.190367. 